\title{
Editorial
}

\section{Tissue Engineering and Dental Implantology: Biomaterials, New Technologies, and Stem Cells}

\author{
Gilberto Sammartino, ${ }^{1}$ David M. Dohan Ehrenfest, ${ }^{2,3}$ \\ Jamil A. Shibli, ${ }^{4}$ and Pablo Galindo-Moreno ${ }^{5}$ \\ ${ }^{1}$ Department of Oral Surgery, Faculty of Medicine, University of Naples Federico II, Via Pansini 5, Edificio 14, 80131 Naples, Italy \\ ${ }^{2}$ Department of Oral and Maxillofacial Surgery, University of Michigan Health System, Ann Arbor, MI 48109-1078, USA \\ ${ }^{3}$ LoB5 Research Unit, School of Dentistry and Research Center for Biomineralization Disorders, Chonnam National University, \\ Gwangju 500-757, Republic of Korea \\ ${ }^{4}$ Department of Periodontology and Oral Implantology, Dental Research Division, University of Guarulhos, Guarulhos, SP, Brazil \\ ${ }^{5}$ Oral Surgery and Implant Dentistry Department, School of Dentistry, University of Granada, Granada, Spain
}

Correspondence should be addressed to Gilberto Sammartino; gilberto.sammartino@unina.it

Received 22 February 2016; Accepted 1 March 2016

Copyright (C) 2016 Gilberto Sammartino et al. This is an open access article distributed under the Creative Commons Attribution License, which permits unrestricted use, distribution, and reproduction in any medium, provided the original work is properly cited.

Over the past 2 decades, tissue engineering has emerged as an alternative technique to repair and restore function of damaged or diseased tissues, and this research topic is growing quickly in the clinical fields. Through translational and transdisciplinary research, tissue engineering combines the attributes of biochemical and biomaterial engineering with the aim of creating bioartificial tissues and organs. For the oral and maxillofacial surgeon, the reconstruction of maxillofacial defects in hard and soft tissues is an ongoing challenge; therefore, the new clinical applications of tissue engineering are important endeavors in oral surgery in general and dental implantology and periodontology in particular.

These new techniques are often combined with new digital approaches (digital radiology and treatment planning, optical imprint, CAD-CAM design of materials, etc.) in order to plan complex rehabilitation, to guide surgical steps related to the prosthetic plan, or to design custom-made biomaterials for tissue engineering applications, for example. Digital dentistry is a wide topic regrouping any dental technology or device that incorporates digital or computercontrolled components, in contrast to that of mechanical or electrical components alone. This new aspect of dentistry is growing very fast in the field and is strong support for tissue engineering and dental implantology. It is an exciting time to be in the dental profession as more technologies are being introduced, which make dentistry safer, faster, more enjoyable, and often better as a whole. These digital technologies are rapidly advancing: new tools such as intra/extraoral scanners [1], cone beam computed tomography (CBCT) scanners $[2,3]$, computer-aided design/computer-aided manufacturing $(\mathrm{CAD} / \mathrm{CAM})$ software [4], and innovative fabrication procedures such as $3 \mathrm{D}$ printing and layered manufacturing are changing the way we treat our patients $[5,6]$.

In parallel to this digital evolution, the stem cells experimental development is a fundamental part of tissue engineering research. Recently, for example, human umbilical cord mesenchymal stem cells (hUCMSCs) have been regarded as a promising candidate for tissue regeneration. Furthermore, it has been reported that hUCMSCs can be induced into odontoblast-like cells in vitro and in vivo [7]. Even the dental pulp stem cells (DPSCs) were explored, due to their rapid proliferation and capability of forming woven bone in vitro and compact bone in vivo; and studies are searching for the factors that trigger the osteogenic differentiation of DPSCs for their potential use in bone tissue engineering. Many therapeutic protocols using stem cells are daily tested for different pathologies.

If stem cells and digital developments are important, they are only two elements of the wide range of technologies 
under development in the domain of tissue engineering. Biomaterials are also a major component of tissue engineering, particularly implantable materials and biological agents as a very active field of clinical regenerative medicine. Implantable biomaterials can take numerous forms and their applications constitute a major source of innovation and investigation: new bone materials, new titanium or ceramic implant design and surfaces, new surgical adjuvants such as platelet concentrates, and so forth. The objectives of all these biomaterials are to repair and to restore function of damaged or diseased tissues and sometimes to promote tissue regeneration. In parallel, the understanding and developments of molecular mediators or biologic agents have increased in the last decade, especially in periodontology and dental implantology. For example, biological agents such as recombinant human Platelet-Derived Growth Factor (rhPDGF$\mathrm{BB})$, Enamel Matrix Derivate (EMD), and Bone Morphogenetic Proteins (BMPs) [8] and various forms of platelet concentrates (Platelet-Rich Plasma (PRP) and Platelet-Rich Fibrin (PRF)) have been used in many clinical situations, with interesting results in periodontal regeneration and bone augmentation procedures $[9,10]$.

As it was previously stated [11], these research fields are the most active translational research topics in orofacial sciences. Any research about these new implantable materials or techniques requires basic sciences research, in vitro and in vivo. For example, the understanding and development of Leukocyte- and Platelet-Rich Fibrin (L-PRF) and associated biotechnologies, which are nowadays one of the growing topics for applied clinical regenerative medicine $[9,10,12]$, require pharmacologic, biological, and tissue engineering concepts to be tested, validated, optimized, and finally redeveloped for extended applications in other fields $[13,14]$. Finally, implantable materials are also good examples of translational research as they require accurate engineering of the chemical and morphological characteristics of the materials [15], their correlation and validation with biological behaviors and concepts, their validation in vivo and in humans, and finally the understanding of their long-term clinical outcomes and eventual pathologies, as previously stated [11].

In conclusion, we are now living in the early era of tissue engineering and regenerative medicine, and applications are numerous in dental implantology. New biomaterials and technologies are the key for the development of this field, and their development requires a significant endeavor in translational and multidisciplinary research, to satisfy the needs for clarity, efficiency, and reproducibility of this still pioneer field.

\section{Acknowledgments}

This work and special issue about new biomaterials and regenerative medicine strategies was supported by the POSEIDO Academic Consortium (Periodontology, Oral Surgery, Esthetic \& Implant Dentistry Organization), by a grant from the National Research Foundation of Korea (NRF) funded by the Korean Government (MEST) (no. 20110030121), and by the LoB5 Foundation for Research, France.
The authors also want to thank Ms. Lidia M. Wisniewska, from the Department of Didactics and School Organization, Faculty of Education Sciences, University of Granada, Granada, Spain, and Department of International Relations, Paris-Sorbonne University, Paris, France, for her help and contribution to the management of this special issue.

\section{Gilberto Sammartino David M. Dohan Ehrenfest Jamil A. Shibli \\ Pablo Galindo-Moreno}

\section{References}

[1] E. Chalmers, G. McIntyre, W. Wang, T. Gillgrass, C. B. Martin, and P. A. Mossey, "Intraoral 3D scanning or dental impressions for the assessment of dental arch relationships in cleft care: which is superior?" The Cleft Palate-Craniofacial Journal, 2015.

[2] R. Jacobs and M. Quirynen, "Dental cone beam computed tomography: justification for use in planning oral implant placement," Periodontology 2000, vol. 66, no. 1, pp. 203-213, 2014.

[3] H. J. Khoury, M. E. Andrade, M. W. Araujo, I. V. Brasileiro, R. Kramer, and A. Huda, "Dosimetric study of mandible examinations performed with three cone-beam computed tomography scanners," Radiation Protection Dosimetry, vol. 165, no. 1-4, pp. 162-165, 2015.

[4] J. S. Shim, J. S. Lee, J. Y. Lee, Y. J. Choi, S. W. Shin, and J. J. Ryu, "Effect of software version and parameter settings on the marginal and internal adaptation of crowns fabricated with the CAD/CAM system," Journal of Applied Oral Science, vol. 23, no. 5, pp. 515-522, 2015.

[5] C. H. F. Hämmerle, L. Cordaro, N. van Assche et al., "Digital technologies to support planning, treatment, and fabrication processes and outcome assessments in implant dentistry. Summary and consensus statements. The 4th EAO consensus conference 2015," Clinical Oral Implants Research, vol. 26, supplement 11, pp. 97-101, 2015.

[6] M. Vercruyssen, T. Fortin, G. Widmann, R. Jacobs, and M. Quirynen, "Different techniques of static/dynamic guided implant surgery: modalities and indications," Periodontology 2000, vol. 66, no. 1, pp. 214-227, 2014.

[7] Y. Chen, Y. Yu, L. Chen et al., "Human umbilical cord mesenchymal stem cells: a new therapeutic option for tooth regeneration," Stem Cells International, vol. 2015, Article ID 549432, 11 pages, 2015.

[8] U.-W. Jung, I.-K. Lee, J.-Y. Park, D. S. Thoma, C. H. F. Hämmerle, and R. E. Jung, "The efficacy of BMP-2 preloaded on bone substitute or hydrogel for bone regeneration at periimplant defects in dogs," Clinical Oral Implants Research, vol. 26, no. 12, pp. 1456-1465, 2015.

[9] M. Del Corso, A. Vervelle, A. Simonpieri et al., "Current knowledge and perspectives for the use of Platelet-Rich Plasma (PRP) and Platelet-Rich Fibrin (PRF) in oral and maxillofacial surgery part 1: periodontal and dentoalveolar surgery," Current Pharmaceutical Biotechnology, vol. 13, no. 7, pp. 1207-1230, 2012.

[10] A. Simonpieri, M. Del Corso, A. Vervelle et al., "Current knowledge and perspectives for the use of Platelet-Rich Plasma (PRP) and Platelet-Rich Fibrin (PRF) in oral and maxillofacial surgery part 2: bone graft, implant and reconstructive surgery," Current Pharmaceutical Biotechnology, vol. 13, no. 7, pp. 12311256, 2012. 
[11] D. M. Dohan Ehrenfest, H.-L. Wang, J.-P. Bernard, and G. Sammartino, "New biomaterials and regenerative medicine strategies in periodontology, oral surgery, esthetic and implant dentistry," BioMed Research International, vol. 2015, Article ID 210792, 3 pages, 2015.

[12] G. Marenzi, F. Riccitiello, M. Tia, A. di Lauro, and G. Sammartino, "Influence of leukocyte- and platelet-rich fibrin (LPRF) in the healing of simple postextraction sockets: a splitmouth study," BioMed Research International, vol. 2015, Article ID 369273, 6 pages, 2015.

[13] G. Sammartino, M. Del Corso, L. M. Wisniewska et al., "The PACT (Platelet \& Advanced Cell Therapies) forum: fostering translational research, transdisciplinarity and international collaboration in tissue engineering and regenerative medicine," POSEIDO, vol. 2, no. 2, pp. 105-115, 2014.

[14] D. M. Dohan Ehrenfest, B. S. Kang, M. Del Corso et al., "The impact of the centrifuge characteristics and centrifugation protocols on the cells, growth factors and fibrin architecture of a Leukocyte- and Platelet-Rich Fibrin (L-PRF) clot and membrane. Part 1: evaluation of the vibration shocks of 4 models of table centrifuges for L-PRF," POSEIDO, vol. 2, no. 2, pp. 129-139, 2014.

[15] D. M. Dohan Ehrenfest, P. G. Coelho, B.-S. Kang, Y.-T. Sul, and T. Albrektsson, "Classification of osseointegrated implant surfaces: materials, chemistry and topography," Trends in Biotechnology, vol. 28, no. 4, pp. 198-206, 2010. 

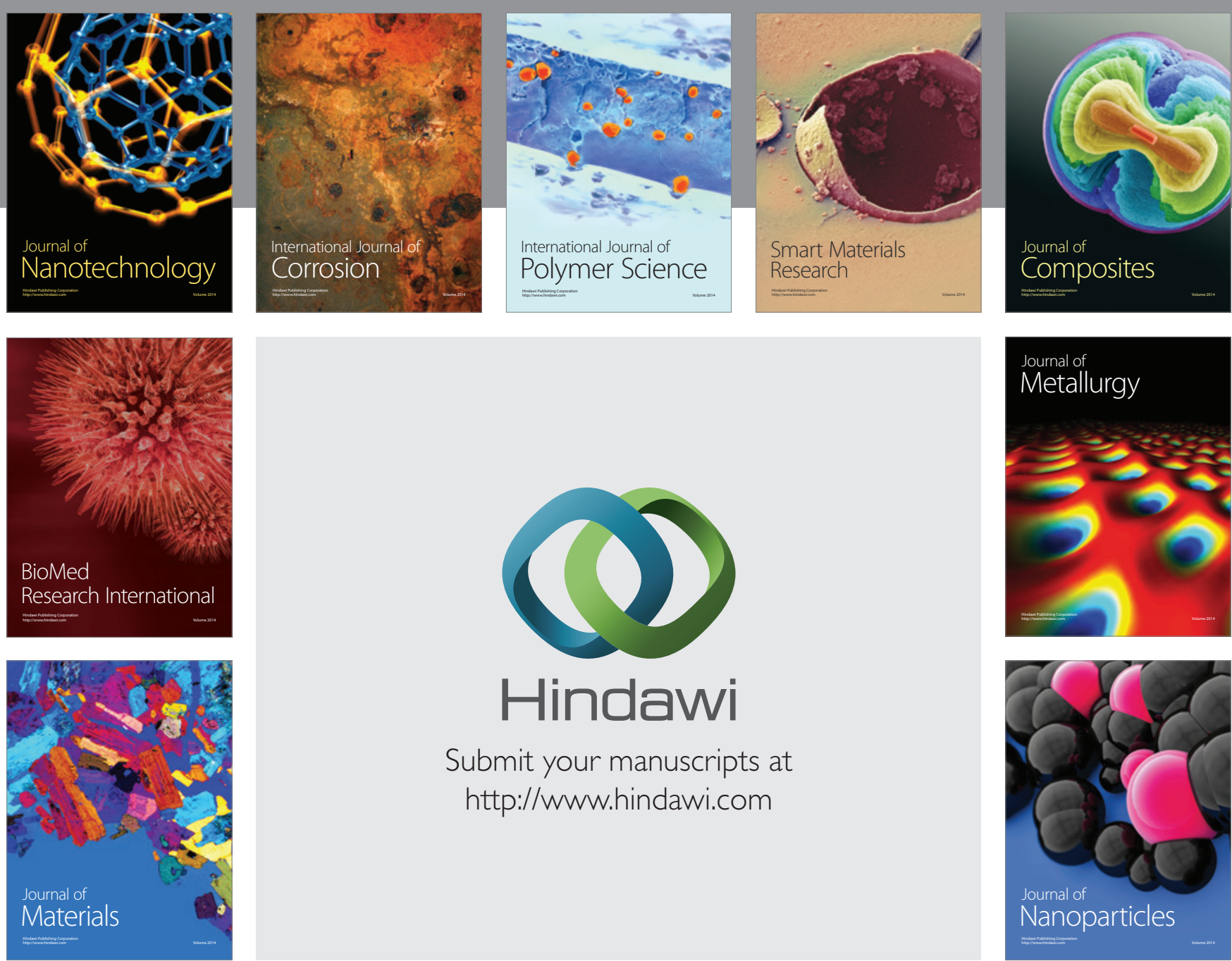

\section{Hindawi}

Submit your manuscripts at

http://www.hindawi.com

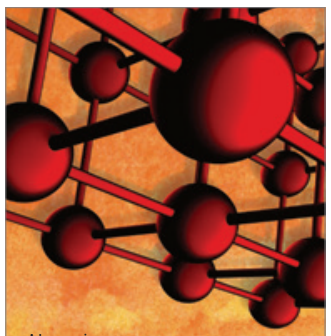

Materials Science and Engineering
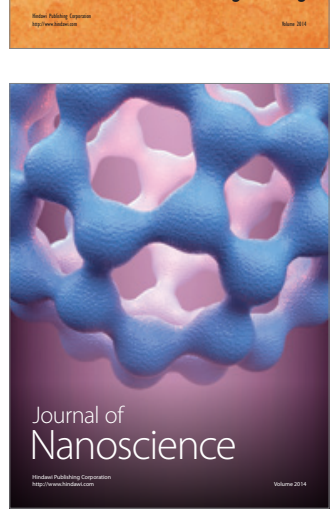
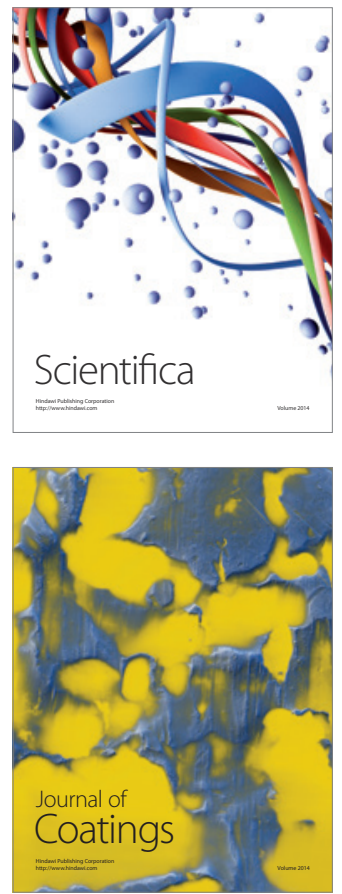
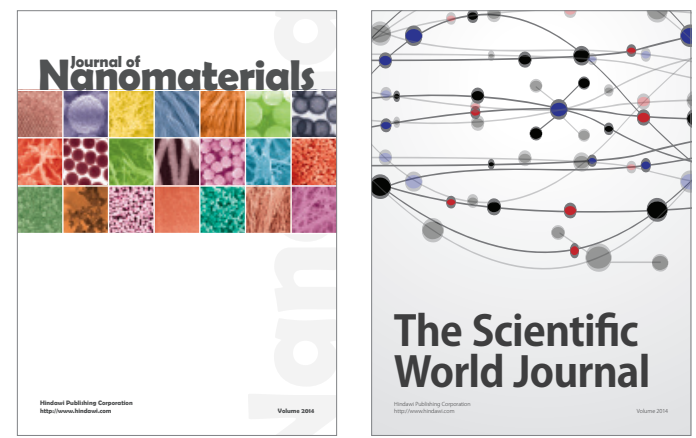

The Scientific World Journal
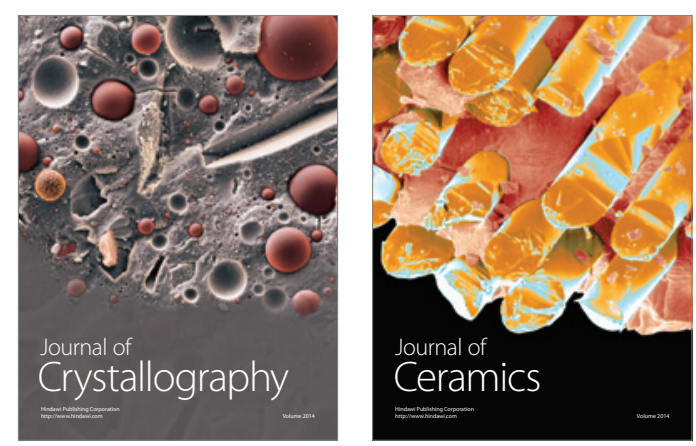
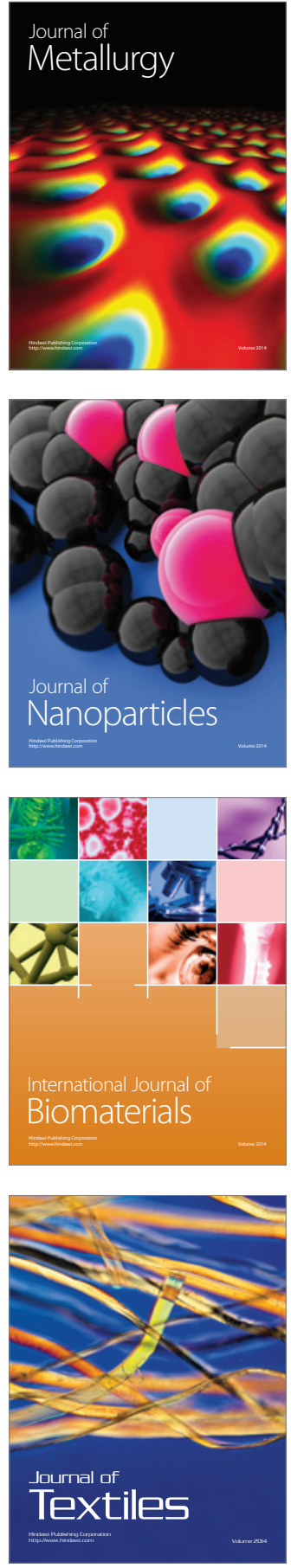